\title{
Free radical facilitated damage of ungual keratin
}

Rajeshree H. Khengar ${ }^{1}$, Marc B. Brown ${ }^{2,3}$, Rob B. Turner ${ }^{2}$, Matthew J. Traynor $^{3}$, Katherine B. Holt ${ }^{4}$, ${ }^{*}$ Stuart A. Jones ${ }^{1}$

${ }^{1}$ Pharmaceutical Science Division, King's College London, Franklin-Wilkins Building, 150 Stamford Street, London, SE1 9NH.

${ }^{2}$ MedPharm Ltd, Unit 3 Chancellor Court, 50 Occam Road, Surrey Research Park, Guildford, GU2 7YN.

${ }^{3}$ School of Pharmacy, University of Hertfordshire, College Lane, Hatfield, Hertfordshire, AL10 9AB.

${ }^{4}$ Department of Chemistry, University College London, Gower Street, London, WClE $6 B T$

*Corresponding author: stuart.jones@kcl.ac.uk; Phone Number: +44 (0)207 848 4843; Fax Number: +44 (0)207 8484800 


\section{ABSTRACT}

Thioglycolic acid (TA) and urea hydrogen peroxide (urea $\mathrm{H}_{2} \mathrm{O}_{2}$ ) are thought to disrupt $\alpha$-keratin disulphide links in the nail. However, optimal clinical use of these agents to improve the treatment of nail disorders is currently hindered by a lack of fundamental data to support their mechanism of action. The aim of this study was to investigate how the redox environment of ungual keratin, when manipulated by TA and urea $\mathrm{H}_{2} \mathrm{O}_{2}$, influenced the properties of the nail barrier. Potentiometric and voltammetric measurements demonstrated that urea $\mathrm{H}_{2} \mathrm{O}_{2}$ obeyed the Nernst equation for a proton coupled one-electron transfer redox process whilst TA underwent a series of redox reactions that was complicated by electrode adsorption and dimer formation. The functional studies demonstrated that nail permeability; measured through TBF penetration $\left(38.51 \pm 10.94 \mu \mathrm{g} / \mathrm{cm}^{2} / \mathrm{h}\right)$ and nail swelling $(244.10 \pm 14.99 \%$ weight increase), was greatest when relatively low concentrations of the thiolate ion was present in the applied solution. Limiting the thiolate ion to low levels in the solution retards thiolate dimerisation and generates thiyl free radicals. It appeared that this free radical generation was fundamental in facilitating the redox mediated keratin disruption of the ungual membrane.

Keywords: $\quad$ nail, onychomycosis, ungual, thioglycolic acid, disulphide, redox 


\section{INTRODUCTION}

The most distinctive physical property of the human nail plate is its strength, which is believed to be a result of its high $\alpha$-keratin content $[1,2]$. Keratins have a large amount of the sulphur-rich amino acid, cysteine [3]. It is the covalent disulphide bonds formed between most of the cysteine molecules (resulting in cystine) during the final stages of protein biosynthesis, that are responsible for this mechanical strength, along with the elastic properties and chemical resistance associated with the nail [4]. The disulphide link has a high bond energy of 200-300 kJ/mol [5,6] compared to hydrogen bonds (10-40 kJ/mol) and van der Waal's interactions (1-20 kJ/mol) hence these cross links are extremely stable in a wide range of environments [7]. The rigidity and hardness of the human nail provides excellent protection for the sensitive finger tips, but it makes local drug delivery extremely difficult. This presents a serious problem for a large cohort of patients as highly prevalent nail disorders such as onychomycosis and nail psoriasis are, at present, inadequately treated using oral medication [8,9]. An effective topical therapy for ungual disease is required, but in order to bypass the highly effective nail barrier a fundamental understanding of how $\alpha$-keratin influences the physical properties of the human nail is required.

Several compounds including cysteine, dithiothreitol, thioglycolic acid (TA) and urea hydrogen peroxide (urea $\mathrm{H}_{2} \mathrm{O}_{2}$ ) are known to diminish the barrier properties of the nail $[10,11]$. Of these compounds, those that have a thiol group attached and hence reducing properties, are generally applied under conditions where the thiol moiety is ionised. For example, TA, a well characterised reducing agent that is included in several commercial depilatory and hair care products, is usually applied at $\mathrm{pH}$ values 
above 10 in order to optimise disruption by the thiolate ion $[12,13]$. It has been hypothesised that TA compromises hair fibre integrity through the cleavage of $\alpha$ keratin disulphide links; an electrochemically driven reversible reduction reaction [14], but there is no direct evidence to support this hypothesis. Urea $\mathrm{H}_{2} \mathrm{O}_{2}$, a stable adjunct of $\mathrm{H}_{2} \mathrm{O}_{2}$ which releases $\mathrm{H}_{2} \mathrm{O}_{2}$ upon contact with water, is also used as a depilatory product. Under strongly oxidative conditions, $\mathrm{H}_{2} \mathrm{O}_{2}$ is also reported to cleave disulphide links via an oxidative fission process $[14,15]$, but again this is not supported by direct analytical evidence.

Despite their current applications in the hair care industry, TA and urea $\mathrm{H}_{2} \mathrm{O}_{2}$ are not employed commercially to enhance permeation into the human nail even though previous research has demonstrated their ability to manipulate ungual keratin $[10,11,16]$. The nail poses a rigid barrier that displays a higher density compared to other similar tissues such as the hair and skin, therefore prior to utilising these agents in chronic clinical testing a detailed understanding of their interaction with ungual constituents is required.

This study was designed to test the hypothesis that sequential use of TA and urea $\mathrm{H}_{2} \mathrm{O}_{2}$ alter the barrier properties of keratin containing tissues through the spontaneous induction of redox mediated disulphide bond breakage. It was thought that the two agents break disulphide bonds via two different mechanisms and this provides them with ability to elicit an enhancement effect. Direct electrochemical analysis of ungual keratin could provide the analytical data to test this hypothesis, but the high density and the tight packing of $\alpha$-keratin renders direct analysis of the protein in situ impossible using standard analytical techniques. Therefore, in this work the human 
nail keratin was exposed to a series of well defined redox environments (using TA and urea $\mathrm{H}_{2} \mathrm{O}_{2}$ to manipulate the redox potentials) and the disulphide bond breakage was assessed by monitoring functional effects such as water uptake and drug permeation after chemical treatment. The objectives of this study were two-fold: first, to investigate the influence of $\mathrm{pH}$ and concentration on the redox properties of TA and urea $\mathrm{H}_{2} \mathrm{O}_{2}$ using direct potentiometry and differential pulse voltammetry (DPV); second, to assess the effects of the redox environment on nail water uptake and permeation of TBF when the two agents were applied to the nail in a sequential manner. It was anticipated that the results from this work would provide a new understanding of how the electrochemical environment of $\alpha$-keratin dictates ungual barrier properties in the nail and thus allow the development of a strategy to treat ungual disorders topically.

\section{MATERIALS}

TA, urea $\mathrm{H}_{2} \mathrm{O}_{2}$ and tritiated water $\left({ }^{3} \mathrm{H}_{2} \mathrm{O}\right)(1 \mathrm{mCi}$ per $\mathrm{g})$ were purchased from SigmaAldrich (Dorset, UK). TBF was supplied by QueMaCo Ltd (Nottingham, UK). Human nail clippings were donated from healthy volunteers following approval by the King's College Research Ethics Committee - (study ref no. 04/05-126). Calibrated ChubTur ${ }^{\circledR}$ permeation cells were kindly donated by MedPharm Ltd. Ethanol (EtOH) (99.7-100 \%, absolute) and sodium hydroxide was purchased from BDH Chemicals Ltd (Dorset, UK). Phosphate buffered saline (PBS) (0.15 M, pH 7.3) was from Oxoid (Hampshire, UK). Scintillation fluid (hionic fluor) was supplied by Perkin Elmer (Bucks, UK). Triethylamine, orthophosphoric acid, acetonitrile (all 
HPLC grade) and Petri dishes were supplied by Fisher (Leicestershire, UK). The 24well cluster plates were from Costar $^{\circledR}$ (Dorset, UK).

\section{METHODS}

\section{Potentiometric measurements}

To study the effect of concentration on redox potential, TA and urea $\mathrm{H}_{2} \mathrm{O}_{2}$ were prepared in 80:20 deionised water/EtOH (v/v) and deionised water respectively. The solutions were unbuffered initially to remove any potential confounding effects of other electrolytes and the $\mathrm{pH}$ drift across the TA and urea $\mathrm{H}_{2} \mathrm{O}_{2}$ concentration range was monitored (TA: $0.001-20 \%$ w/w, $\mathrm{pH} 2-2.9$; urea $\mathrm{H}_{2} \mathrm{O}_{2}: 0.005-17.5 \%$ w/w $\mathrm{H}_{2} \mathrm{O}_{2}$, pH $3.5-4.2$ ). In subsequent studies the use of a buffer was essential to maintain the $\mathrm{pH}$ of the application solution when in contact with the nail but the use of a phosphate buffer had no influence on the redox potentials of the agents utilised in the study.

To study the effect of $\mathrm{pH}$ on redox potential TA was prepared at $5 \%(\mathrm{w} / \mathrm{w})$ in 80:20 deionised water/EtOH (v/v) and urea $\mathrm{H}_{2} \mathrm{O}_{2}$ was prepared at $2.5 \%\left(\mathrm{w} / \mathrm{w}_{2} \mathrm{H}_{2}\right.$ ) in deionised water. The $\mathrm{pH}$ of each solution was adjusted as required using sodium hydroxide and orthophosphoric acid ( $\mathrm{pH}$ range 2-12). The zero current (standard potential) measurements were performed by measuring the open circuit potential in volts (V) between a carbon working electrode (for TA) or a platinum electrode (for $\left.\mathrm{H}_{2} \mathrm{O}_{2}\right)$ versus a reference electrode $(\mathrm{Ag} / \mathrm{AgCl})$ using a 900B potentiostat $(\mathrm{CH}$ Instruments, Austin, USA) to record each potential output. As the measured potential 
drifted slightly with time, potential values were taken after 60 seconds of putting the electrode in solution. Recorded potentials were converted to the standard hydrogen electrode (SHE) scale using a correction factor of $+208 \mathrm{mV}$. A carbon electrode was employed for potentiometric analysis of TA, as interferences to potential measurements are reported to occur as a result of adsorption of sulphydryls on platinum electrodes [17]. A platinum electrode was used for $\mathrm{H}_{2} \mathrm{O}_{2}$ measurements, as $\mathrm{H}_{2} \mathrm{O}_{2}$ reduction occurs readily at the platinum electrode but sluggishly at carbon electrodes.

\section{Differential pulse voltammetry experiments}

DPV experiments were performed using a $\mu$-Autolab potentiostat controlled by GPES software (Ecochemie, Utrecht, Netherlands). A modulation potential of $0.045 \mathrm{~V}$ with a modulation time of $0.05 \mathrm{~s}$, and a step potential of $0.005 \mathrm{~V}$ with an interval time of $0.5 \mathrm{~s}$ was employed for the measurements. Solutions of TA (analysed using a glassy carbon electrode to minimise sulphur adsorption effects) and urea $\mathrm{H}_{2} \mathrm{O}_{2}$ (analysed using a platinum electrode) were tested at an arbitary concentration of $5 \mathrm{mM}$ (urea $\mathrm{H}_{2} \mathrm{O}_{2}$ solutions had a $\mathrm{H}_{2} \mathrm{O}_{2}$ concentration of $5 \mathrm{mM}$ ) and were buffered at $\mathrm{pH} 2,8$ and 13 using phosphate buffer.

\section{Human nail water uptake}

Infection-free (by visual inspection) human nail clippings were obtained from 15 donors $(n=10)$. Nail clippings were trimmed to attain a weight range of 9-12 $\mathrm{mg}$, washed with $70 \% \mathrm{EtOH}(\mathrm{v} / \mathrm{v})$ and rinsed in deionised water. The nails were allowed 
to dry overnight in an open Petri dish at room temperature and stored in a clean glass container at $4{ }^{\circ} \mathrm{C}$ prior to use. To conduct the water uptake test, the clean, dry nails were weighed and placed into individual wells of a 24-well plate. An aliquot of the appropriate solution $(1 \mathrm{ml})$ containing either TA or urea $\mathrm{H}_{2} \mathrm{O}_{2}$ at an appropriate buffered $\mathrm{pH}$ was added to each well so that nail samples were submerged. The plates were covered using lids and incubated at room temperature for $20 \mathrm{~h}$. After incubation the nails were removed from solution and placed into the clean wells of a fresh 24well plate. The nail clippings were briefly rinsed 3 times $(1 \mathrm{ml}$ each time) with deionised water to remove residual solution. Excess moisture was eliminated from each clipping using clean tissue towels after which the second PE (1 ml) was added to each well. The plates were covered with lids and incubated at room temperature for a further $20 \mathrm{~h}$. The nail clippings were finally removed from each well and individually reweighed following the removal of excess moisture using clean tissue.

\section{Permeation studies}

Clean, dry $3 \mathrm{~mm}^{2}$ nail sections (cleaned as per the nail swelling experiments), were clamped and held in place between receiver and donor chambers of pre-calibrated ChubTur $^{\circledR}$ permeation cells, details of which are published in earlier work $[10,11]$. Buffered TA solutions $(0.5 \mathrm{ml})$ were applied to the donor compartments of permeation cells so that the exposed dorsal surfaces $\left(0.05 \mathrm{~cm}^{2}\right)$ of each nail were submerged. Donor chambers were covered with parafilm to minimise solvent evaporation and the cells were incubated at room temperature for $20 \mathrm{~h}$. Following incubation the TA solution was removed and the donor compartment flooded 3 times with deionised water to remove any residual solvent. Any remaining moisture was 
eliminated using a clean tissue towel. Urea $\mathrm{H}_{2} \mathrm{O}_{2}$ solution was applied using the same method and cells were incubated for an additional $20 \mathrm{~h}$ at room temperature. The urea $\mathrm{H}_{2} \mathrm{O}_{2}$ solution was removed and donor compartments were rinsed 3 times with deionised water for the final time.

The receiver compartments of each ChubTur ${ }^{\circledR}$ cell were filled to the calibration mark with receiver fluid (50:50 EtOH/PBS). Each diffusion cell was equilibrated for $30 \mathrm{~min}$ in a water bath maintained at $32{ }^{\circ} \mathrm{C}$ which was employed in order to keep the enclosed dorsal nail surface temperature at a physiologically relevant temperature of ca. $28{ }^{\circ} \mathrm{C}$ [18] (verified using a k-type insulated wire probe; Hanna Instruments, Bedfordshire, UK). TBF was prepared in a 50:50 $\mathrm{PBS} / \mathrm{EtOH}$ solution and used at a saturated concentration (to maintain the drug thermodynamic activity constant) by adding an excess of solid compound to the solvent $(20 \mathrm{ml})$ and stirring until equilibration was achieved ( $2 \mathrm{~h}$, data not shown). The drug suspension was filtered using a $0.45 \mu \mathrm{m}$ syringe filter (Nalgene, Hereford, UK) at room temperature to produce the saturated TBF solution (the $\mathrm{pH}$ of the filtered saturated solution was 3.0). To initiate the experiment, the prepared TBF solution was applied $(0.5 \mathrm{ml})$ to the dry, clean donor compartments of the permeation cells. The donor compartments and sampling arms of each cell were sealed with parafilm for the duration of the experiment. The receiver compartment of each diffusion cell was sampled $(1 \mathrm{ml})$ at pre-determined time points over a period of $195 \mathrm{~h}$. Cumulative amounts of $\mathrm{TBF}(\mu \mathrm{g})$ that penetrated the nail per surface area $\left(\mathrm{cm}^{2}\right)$ were corrected for previous sample removal and plotted against time (h). 
Following each nail permeation study, an integrity check of the cells was performed at $32{ }^{\circ} \mathrm{C}$ using ${ }^{3} \mathrm{H}_{2} \mathrm{O}$, a well characterised permeability marker [19]. Prior to the application of ${ }^{3} \mathrm{H}_{2} \mathrm{O}$, the donor compartments of cells were washed by flooding 3 times with deionised water to remove any residual drug. Remaining moisture was removed from the donor chambers using clean tissues and the fluid in the receiver chamber was replaced with fresh deionised water. A $0.2 \mathrm{ml}$ aliquot of ${ }^{3} \mathrm{H}_{2} \mathrm{O}(3.7$ $\mathrm{Bq} / \mathrm{ml})$ was applied to the donor chamber of each ChubTur ${ }^{\circledR}$ cell. Samples $(1 \mathrm{ml})$ were removed from the receiver chamber of each cell after $1 \mathrm{~h}$ and $20 \mathrm{~h}$ and were placed directly into scintillation vials to which $4 \mathrm{ml}$ of scintillation fluid was added. The vials were closed, mixed thoroughly by hand and analysed using a LS 6500 multipurpose scintillation counter (Beckman Coulter ${ }^{\mathrm{TM}}$, Buckinghamshire, UK). The radioactivity was quantified as disintegrations per minute (DPM) which are independent of quenching effects observed in liquid scintillation [20]. Cells were rejected if total DPM at $1 \mathrm{~h}$ was on average more than $20 \%$ higher than the mean of the other cells that had undergone the same pre-treatment or if the total DPM at $20 \mathrm{~h}$ was on average more than $40 \%$ higher than the mean of the other cells that had undergone the same pre-treatment. These values were used as it would not be expected for nail drug permeation variability to exceed $20 \%$ after $1 \mathrm{~h}$ or $40 \%$ after $20 \mathrm{~h}$ when a varied nail sample pool is utilised $[10,11]$.

\section{Data analysis}

Results from the human nail swelling and TBF flux studies are expressed as the means of 8-10 and 3-8 replicates \pm SD respectively. For TBF flux, the slope of the linear portion of TBF concentration versus time profiles $\left(R^{2} \geq 0.95\right)$ was defined as 
the steady state flux. The data was tested for normality (Shapiro-Wilk test) and statistical analysis was performed using the non-parametric Mann-Whitney test (SPSS $^{\circledR}$ for Windows 11.0.0). A level of $P \leq 0.05$ was considered significant.

\section{RESULTS}

\section{Dependence of solution redox potential on concentration of redox species and pH}

The zero current redox potentials were measured for solutions with a range of TA concentrations, at pH 2 -2.9, using a carbon working electrode. Fig 1 a shows that at lower TA concentrations a linear relationship was observed between the measured cell potential, $E$ (vs. SHE) and the natural $\log$ of the TA concentration $\left(R^{2}=0.99\right)$ with a slope of $-26 \mathrm{mV}$. As TA concentration was increased, $E$ became independent of TA and reached a plateau value of ca. $E=0.26 \mathrm{~V}$ vs. SHE. In contrast, Fig $1 \mathrm{~b}$ shows that for urea $\mathrm{H}_{2} \mathrm{O}_{2}$, a linear relationship was obtained between the natural $\log$ of concentration and $E$ at a platinum electrode, over the full investigated concentration range, with a slope of $19 \mathrm{mV}\left(R^{2}=0.92\right)$.

The redox potential of $5 \% \mathrm{TA}(\mathrm{w} / \mathrm{w})$ solution also exhibited a $\mathrm{pH}$ dependent response (Fig 2 a). From pH 3 to $\mathrm{pH}$ 9.5, an approximately linear relationship was observed between $\mathrm{pH}$ and $E$, with a slope of $-48 \mathrm{mV}\left(R^{2}=0.98\right)$. The break point observed in the plot at ca. pH 10 was close to the thiol pKa value for TA (pKa 10.31). At pH 10 and above, there does not appear to be a simple relationship between $\mathrm{pH}$ and $E$. Positive $E$ values were observed for $2.5 \%$ urea $\mathrm{H}_{2} \mathrm{O}_{2}\left(2.5 \%\right.$ w/w $\left.\mathrm{H}_{2} \mathrm{O}_{2}\right)$ over the whole tested $\mathrm{pH}$ range ( $\mathrm{pH}$ 2-12) using the platinum electrode (Fig 2 b) which implied 
urea $\mathrm{H}_{2} \mathrm{O}_{2}$ reduction was favoured with respect to SHE under these conditions. Between $\mathrm{pH} 2$ and $\mathrm{pH} 9$ a linear relationship between $\mathrm{pH}$ and $E$ is observed, with a slope of $-58 \mathrm{mV}\left(R^{2}=0.99\right)$. A break point was present in the urea $\mathrm{H}_{2} \mathrm{O}_{2}$ electrochemical profile at ca. $\mathrm{pH} 9.5$, which is relatively consistent with the $\mathrm{pKa}$ (11.6) for $\mathrm{H}_{2} \mathrm{O}_{2}$.

\section{Redox species analysis using differential pulse voltammetry (DPV)}

Zero current cell potential measurements, as above, give some indication of the redox environment of a solution; however they give no information as to the identity of the solution redox species. Voltammetric techniques, such as cyclic voltammetry are thus used to determine the concentrations of solution redox species and the potential at which they undergo oxidation or reduction. In this study differential pulse voltammetry (DPV) was used, due to its ability to resolve the current response of species that have similar potentials and thus overlapping peaks.

DPV analysis of $5 \mathrm{mM}$ TA buffered at $\mathrm{pH} 2$ identified two poorly defined and broad anodic waves at relatively high potentials of +1.3 and $+1.6 \mathrm{~V}$ (vs. SHE) (Fig 3 a) attributed to the oxidation of TA at the carbon electrode. A significantly smaller anodic peak at $\mathrm{pH} 2$ was also observed at a much lower potential $(+0.4 \mathrm{~V}$, see inset to Fig 3 a). When the TA was buffered at $\mathrm{pH} 8$, the anodic waves appeared at similar potentials to the $\mathrm{pH} 2$ solutions but the measured currents were about 4-5 times smaller (Fig 3 b). For the TA solution buffered at $\mathrm{pH}$ 13, the two anodic peaks were shifted to $+0.9 \mathrm{~V}$ and $+1.2 \mathrm{~V}$ (Fig $3 \mathrm{c}$ ). The TA peaks were broad and not fully 
resolved at any of the pHs tested which indicated a complex and multi-component, multi-step oxidation process.

The reduction behaviour of urea $\mathrm{H}_{2} \mathrm{O}_{2}$ was also investigated using DPV. Scans of urea $\mathrm{H}_{2} \mathrm{O}_{2}$ (5 mM H $\mathrm{H}_{2} \mathrm{O}_{2}$ ) solutions showed cathodic waves when it was dissolved in vehicles at $\mathrm{pH} 2,8$ and 13, which indicated species reduction occurred irrespective of pH. At pH 2, two unresolved cathodic peaks at $+0.2 \mathrm{~V}$ and $+0.4 \mathrm{~V}$ (Fig 4 a) were observed. The response at $\mathrm{pH} 8$ was more complex (Fig 4 b), with three overlapping peaks observed at $+0.1 \mathrm{~V},+0.3 \mathrm{~V}$ and $+0.5 \mathrm{~V}$. When urea $\mathrm{H}_{2} \mathrm{O}_{2}$ was buffered at $\mathrm{pH} 13$ only a single peak was present in the DPV scan at $+0.05 \mathrm{~V}$ (Fig $4 \mathrm{c}$ ). The urea $\mathrm{H}_{2} \mathrm{O}_{2}$ solution appeared to contain the most redox active species at a high $\mathrm{pH}$.

\section{Water uptake and TBF permeability}

The human nail samples were exposed to a sequence of two electrochemical environments (a vehicle containing TA followed by a vehicle containing urea $\mathrm{H}_{2} \mathrm{O}_{2}$ ) and their capacity to take up water and allow the passage of TBF was assessed. The greatest water uptake was through nails pre-treated with $15 \%$ TA $(w / w)$ at $\mathrm{pH} 2$ followed by $15 \%$ urea $\mathrm{H}_{2} \mathrm{O}_{2}\left(15 \% \mathrm{H}_{2} \mathrm{O}_{2}\right.$, w/w $)$ at $\mathrm{pH}$ 3.4. This sequence of electrochemical environments also resulted in the highest recorded TBF nail flux (Table 1). When the concentration of TA was lowered to $5 \%(\mathrm{w} / \mathrm{w})$, and the $\mathrm{pH}$ of TA maintained at 2 , the second fastest $\mathrm{TBF}$ ungual flux rate and water uptake was attained. At $\mathrm{pH} 8$, irrespective of concentration, the effect of TA on both TBF permeation and water uptake was statistically lower $(P<0.05)$ compared to corresponding experiments when TA was applied to the nail at $\mathrm{pH}$ 2. For example, increasing the $\mathrm{pH}$ of $5 \% \mathrm{TA}(\mathrm{w} / \mathrm{w})$ from 2 to 8 resulted in a rate of TBF flux that was 
ca. $83 \%$ lower and an increase in nail weight that was approximately $50 \%$ less. The ungual permeability experiments, conducted over $195 \mathrm{~h}$, demonstrated the ability of TBF to permeate full thickness nail plates passively and produce a steady-state permeation profile between ca. 123 - 195 h (Fig 5).

The influence of urea $\mathrm{H}_{2} \mathrm{O}_{2} \mathrm{pH}$ on water uptake and $\mathrm{TBF}$ permeation when the nail was exposed to a series of two different electrochemical environments was less than that observed for TA, but the effects of urea $\mathrm{H}_{2} \mathrm{O}_{2}$ concentration were significant in some cases. For example, when TA was fixed at a pH of 5, the highest TBF nail flux and the greatest increases in nail weight were observed when a $15 \%$ urea $\mathrm{H}_{2} \mathrm{O}_{2}(\mathrm{w} / \mathrm{w}$ $\mathrm{H}_{2} \mathrm{O}_{2}$ ) solution at $\mathrm{pH} 8$ was applied to the human nails following TA exposure. Employing identical conditions but lowering the $\mathrm{pH}$ of the urea $\mathrm{H}_{2} \mathrm{O}_{2}$ in solution to pH 2 had no significant effect $(P \geq 0.05)$ on nail water uptake or TBF permeation. However, a decrease in the concentration from 15 to $5 \%$ urea $\mathrm{H}_{2} \mathrm{O}_{2}\left(\mathrm{w} / \mathrm{w} \mathrm{H}_{2} \mathrm{O}_{2}\right)$ at $\mathrm{pH}$ 8 did result in a significantly lower nail weight increase (54\% lower) and a dramatic decrease in TBF flux (98\% lower). The concentration dependent effect of urea $\mathrm{H}_{2} \mathrm{O}_{2}$ was also observed when it was applied at pH 2 (Table 1).

\section{DISCUSSION}

The relevance of redox chemistry in the manipulation of disulphides and therefore nail barrier function is demonstrated by the numerous accounts of disulphide reactions under reductive or oxidative conditions $[15,21]$. TA has previously been reported to break disulphide bonds most efficiently through electrochemical reduction at $\mathrm{pHs}$ of > 8 , as the active species is believed to be the thiolate ion, ${ }^{-} \mathrm{S}^{-} \mathrm{CH}_{2}-\mathrm{COO}^{-}$, which is only 
present at alkaline $\mathrm{pH}$ due to dissociation of the thiol group $[13,14]$. In the present study however, it was found that the flux of TBF through nails that had been sequentially exposed to TA and urea $\mathrm{H}_{2} \mathrm{O}_{2}$ solutions was greatest at $\mathrm{pH}$ 2, when the majority of TA molecules were un-ionised. The nail swelling experiments supported these trends. Direct potentiometry and DPV were therefore employed to investigate the redox properties of solutions containing TA and urea $\mathrm{H}_{2} \mathrm{O}_{2}$ to try and understand the reasons for this unexpected loss in nail barrier function when solutions containing low levels of thiolate ions were applied to it.

For the reaction $\mathrm{A}+\mathrm{ne}^{-} \rightarrow \mathrm{B}$, the measured potential in an electrochemical cell can be described by the Nernst equation (Eq. 1) [22]:

$$
E=E^{0}+\frac{\mathrm{RT}}{\mathrm{nF}} \ln \frac{[\mathrm{A}]}{[\mathrm{B}]}
$$

where $E$ is the cell potential, $E^{0}$ is the standard electrochemical potential, $\mathrm{R}$ is the universal gas constant, $\mathrm{T}$ is temperature, $\mathrm{n}$ is the number of electrons transferred per mol, $\mathrm{F}$ is the Faraday constant, $[\mathrm{A}]$ is the concentration of the oxidised species and [B] is the concentration of the reduced species. Fig 1 a shows that a linear relationship between the natural log of TA concentration and redox potential was only observed at the lowest TA concentrations tested $(0.005 \%$ to $0.1 \%)$. As the $\mathrm{pH}$ of the TA solutions in these concentration studies was between $2.0-2.9$, the dominant species in each solution would be the un-ionised TA molecule $\left(\mathrm{HS}-\mathrm{CH}_{2}-\mathrm{COOH}\right)$. Therefore the reaction at the electrode under these conditions would be expected to proceed via Eq. 2, resulting in the generation of the highly reactive thiyl radical. 


$$
\mathrm{HS}-\mathrm{CH}_{2}-\mathrm{COOH} \leftrightarrow{ }^{\bullet} \mathrm{S}-\mathrm{CH}_{2}-\mathrm{COOH}+\mathrm{e}^{-}+\mathrm{H}^{+} \quad \text { Eq. } 2 .
$$

The Nernst equation for this reaction can therefore be written:

$$
E=E^{0}+\frac{\mathrm{RT}}{\mathrm{F}} \ln \frac{\left[\bullet \mathrm{SCH}_{2} \mathrm{COOH}\right]\left[\mathrm{H}^{+}\right]}{\left[\mathrm{HSCH}_{2} \mathrm{COOH}\right]}
$$

A plot of $E$ vs. $\ln \left[\mathrm{HSCH}_{2} \mathrm{COOH}\right]$ is predicted to have a slope of $-\mathrm{RT} / \mathrm{F}$, which at 298 $\mathrm{K}$ is $-26 \mathrm{mV}$, as is observed over the lower TA concentrations in Fig 1 a, confirming the dominant redox process under these conditions is that shown in Eq. 2.

At higher concentrations of TA (1\% to $20 \%)$ the concentration-independent redox potential values recorded at the carbon electrode suggested that an alternative, more complex reaction must be occurring. We suggest that dimerisation of the highly reactive free radical species occurs in more concentrated solution (Eq. 4); this reaction has previously been reported and depletes the available thiyl radicals [23]:

$$
\mathrm{RS}^{\bullet}+\mathrm{RS}^{\bullet} \rightarrow \mathrm{RSSR}
$$

Eq. 4.

where $\operatorname{RS}^{\bullet}$ is the TA free radical species and RSSR is the dimerised TA molecule.

The TA redox measurements were also complicated by the $\mathrm{pH}$ dependent proton exchange that occurred in the solutions, as shown in Fig 2 a. According to Eq 3, a plot of $E$ vs. $\mathrm{pH}\left(\log \left[\mathrm{H}^{+}\right]\right)$should result in a slope of $2.3 \mathrm{RT} / \mathrm{F}$, or $59 \mathrm{mV}$ at $\mathrm{T}=298 \mathrm{~K}$, for 
a simple $1 \mathrm{H}^{+} / 1 \mathrm{e}^{-}$reaction. The slope of the most linear portion of the TA $\mathrm{pH}$ vs. $E$ profile at the carbon electrode was $48 \mathrm{mV}$ (Fig 2 a, $\mathrm{pH} 3$ - 9.5). The deviation of this value from $59 \mathrm{mV}$ predicted by the Nernst equation indicates more complex TA proton exchange dependent redox chemistry than suggested by Eq. 2. At pH 2 the carboxyl group of TA (pKa $=3.67)$ would be less than $3 \%$ ionised whilst the thiol $(\mathrm{pKa}=10.31)$ would be virtually un-ionised. The different proton dependent equilibria over the $\mathrm{pH}$ range and the competing dimerisation reaction of Eq. 4 are likely explanations from the deviation of the relationship from theory. A notable break from linearity in the profile of $E$ vs. $\mathrm{pH}$ of TA occurred at $\mathrm{pH} 10$, close to the pKa of the thiol group, indicating a change in solution redox species upon dissociation of the thiol. The reaction at this higher $\mathrm{pH}$ would be expected to revert to that described by Eq. 5 .

$$
{ }^{-} \mathrm{S}-\mathrm{CH}_{2}-\mathrm{COO}^{-} \leftrightarrow{ }^{\bullet} \mathrm{S}-\mathrm{CH}_{2}-\mathrm{COO}^{-}+\mathrm{e}^{-}
$$

Eq. 5.

Indeed at $\mathrm{pH} 10$ and above, $E$ becomes independent of $\mathrm{pH}$, which is consistent with Eq 5, where protons play no role in the reaction [24,25].

DPV, a sensitive voltammetric technique, was used to identify the redox active species in TA solution. Previous voltammetric studies of sulphydryl compounds such as glutathione, 2-mercaptoethanol, TA and cysteine have shown that thiol oxidation usually occurs at high electrode potentials in the absence of a catalyst [26-28] despite the reported strong reducing nature of the TA molecule in reactions with hair keratin. The DPV scans of TA in Fig 3 agreed with previous electrochemical studies; the oxidation peaks appeared at an electrode potential of $+0.8 \mathrm{~V}$ and above for all TA 
solutions irrespective of $\mathrm{pH}$, which demonstrated the high electrode overpotential for oxidising TA. The least positive potential for TA oxidation was noted for the $\mathrm{pH} 13$ TA solution (ca. $+0.85 \mathrm{~V}$ ), illustrating that oxidation of TA is easier at this $\mathrm{pH}$ compared to $\mathrm{pH} 2$ and 8 (where oxidation occurred at $+1.27 \mathrm{~V}$ ). The comparative ease in oxidising TA at an alkaline $\mathrm{pH}$ was consistent with literature reports of TA being a better reducing agent at high $\mathrm{pH}[14,21]$.

The oxidation peak positions in the DPV scans did not correlate with $E$ values observed for the direct potentiometric analysis data $(+0.4 \mathrm{~V}$ (acidic $\mathrm{pH})$ to $-0.3 \mathrm{~V}$ (alkaline $\mathrm{pH})$ ). This is because the zero current $E$ measurements are dominated by equilibria established at the electrode surface (e.g. as shown in Eqs. 2 and 5) involving only a very small concentration of redox active species in comparison to the bulk concentration. The small anodic peak at $+0.4 \mathrm{~V}$ (see inset to Fig 3 a) when TA was analysed in a $\mathrm{pH} 2$ buffer has previously been assigned to such electrodeadsorbed species [26]. In the absence of a catalyst the oxidation of TA requires much higher applied potentials (a large overpotential) than predicted by the zero current measurements, as observed in the DPVs in Fig 3. At pH 2 and 8 the oxidation peak at 1.3 $\mathrm{V}$ has previously been assigned to the reaction in Eq. 2, after which dimerisation of the radical product occurs immediately (Eq. 4). The second peak at $1.6 \mathrm{~V}$ was assigned to the oxidation of the resulting dimer [28].

The cell potential and DPV results from this study are consistent with previous reports that TA is a better reducing agent at higher $\mathrm{pH}$ (above $\mathrm{pH} 10$ ) as the solution will contain a higher concentration of the active reducing agent ${ }^{-} \mathrm{S}-\mathrm{CH}_{2}-\mathrm{COO}{ }^{-}$. However, contrary to predictions, this study has also found that loss of nail barrier integrity was 
greatest after TA treatment at $\mathrm{pH}$ 2. To explain this we consider the active agent in keratin disulphide bond disruption, which we believe to be the highly reactive thiyl radical. The dominance of the un-ionised TA molecules in solution at low $\mathrm{pH}$ results in its relatively poor reductive ability $(+0.3 \mathrm{~V}$ at $\mathrm{pH} 2$ compared to $-0.1 \mathrm{~V}$ at $\mathrm{pH} 11)$ but provides an adequate supply of the precursor to thiyl radical formation (Eq. 2). The disruption to the disulphide bonds in keratin $(|-\mathrm{S}-\mathrm{S}-|)$ can occur as per Eq. 6 :

$$
\mathrm{RS}^{\bullet}+|-\mathrm{S}-\mathrm{S}-| \rightarrow-\mathrm{S}-\mathrm{S}-\mathrm{R}+{ }^{\bullet} \mathrm{S}-\mid
$$

Eq. 6 demonstrates that a free radical is available to propagate further, reacting with neighbouring disulphide linkages, allowing multiple bonds to be broken before quenching occurs. Quenching can only occur on combination with another radical species, which suggests that this bond breaking mechanism will be most efficient when low concentrations of thiyl radical are present i.e. at $\mathrm{pH} 2$. This is consistent with nail permeability and swelling studies.

Treatment with urea $\mathrm{H}_{2} \mathrm{O}_{2}$ solution after TA exposure was found to further disrupt nail integrity, but the process appeared relatively insensitive to the $\mathrm{pH}$ of the $\mathrm{H}_{2} \mathrm{O}_{2}$ solution. $\mathrm{H}_{2} \mathrm{O}_{2}$ is commonly used to break disulphide bonds, possibly via an oxidative fission process. Redox potential measurements of $E$ vs. ln of urea $\mathrm{H}_{2} \mathrm{O}_{2}$ concentration (Fig $1 \mathrm{~b}$ ) gave a relatively linear response, with slope of $19 \mathrm{mV}$. When $E$ for this electrode process was measured with $\mathrm{pH}$, a linear response was obtained from $\mathrm{pH} 2$ 9, with a slope of $59 \mathrm{mV}$ indicating a $1 \mathrm{e}^{-} / 1 \mathrm{H}^{+}$redox process, such as that in Eq. 7 , with the corresponding Nernst equation shown as Eq 8 . 


$$
\begin{array}{ll}
\mathrm{H}_{2} \mathrm{O}_{2}+\mathrm{H}^{+}+\mathrm{e}^{-} \leftrightarrow \mathrm{H}_{2} \mathrm{O}+{ }^{\bullet} \mathrm{OH} & \text { Eq. 7. } \\
E=E^{O}+\frac{\mathrm{RT}}{\mathrm{F}} \ln \frac{\left[\mathrm{H}_{2} \mathrm{O}_{2}\right]\left[\mathrm{H}^{+}\right]}{\left[\mathrm{H}_{2} \mathrm{O}\right]\left[\mathrm{OH}^{\bullet}\right]} & \text { Eq. 8. }
\end{array}
$$

The deviation from linearity observed in the $\mathrm{pH}$ profile of urea $\mathrm{H}_{2} \mathrm{O}_{2}$ above $\mathrm{pH} 9$ was likely due to the dissociation of $\mathrm{H}_{2} \mathrm{O}_{2}(\mathrm{Eq} .9)(\mathrm{pKa}=11.6)$ and thus the liberation of the perhydroxyl anion in solution; the electrode process would then be described by therefore be expected to change from that described by Eq. 10 .

$$
\begin{aligned}
& \mathrm{H}_{2} \mathrm{O}_{2} \leftrightarrow \mathrm{HO}_{2}^{-}+\mathrm{H}^{+} \\
& \mathrm{HO}_{2}{ }^{-}+\mathrm{H}_{2} \mathrm{O}+2 \mathrm{e}^{-} \leftrightarrow 3 \mathrm{OH}^{-}
\end{aligned}
$$$$
\text { Eq. } 9 .
$$

As the influence of urea $\mathrm{H}_{2} \mathrm{O}_{2}$ on nail barrier properties appeared to be relatively insensitive to $\mathrm{pH}$ this switch in reactive species was assumed to be of negligible importance.

The DPV studies confirmed that at all $\mathrm{pH}$ values tested, $\mathrm{H}_{2} \mathrm{O}_{2}$ solutions were oxidising in nature relative to the SHE, i.e. the solution contained a complex range of redox species that could be reduced at relatively high potentials. We speculate that the additive effect of $\mathrm{H}_{2} \mathrm{O}_{2}$ treatment after treatment with TA may be attributed to the ability of $\mathrm{H}_{2} \mathrm{O}_{2}$ to oxidatively cleave the disulphide bonds formed between the TA and the nail keratin in equation 6 , liberating the reactive thiyl radical, which is then free to react further with the disulphide bonds (Eq. 11) 
$\left|-\mathrm{S}-\mathrm{S}-\mathrm{R}+\mathrm{H}_{2} \mathrm{O}_{2} \rightarrow\right|-\mathrm{S}-\mathrm{O}-\mathrm{H}+\mathrm{RS}^{\bullet}+\mathrm{HO}^{\bullet}$

Eq. 11.

\section{CONCLUSION}

The application of redox active agents undoubtedly increases nail barrier permeation through keratin damage. However, the data generated in this work illustrated that multiple mechanisms of keratin structural modification are simultaneously occurring when sulphur containing compounds are applied to the nail. At a low $\mathrm{pH}$ the TBF permeation studies and the nail swelling experiments demonstrated the superior ability of TA to induce disulphide damage. The reaction equilibria derived from potentiometric analysis suggested that the nail keratin damage was probably driven by a free radical chain reaction. Although TA retained the capacity to induce keratin damage at higher pH's, possibly due to the more standard reduction process via the thiolate ion, the reduced effectiveness of TA at these higher $\mathrm{pH}$ values indicated a quenching in thiyl radical activity. Urea $\mathrm{H}_{2} \mathrm{O}_{2}$ displayed current potential profiles that mimicked previously reported studies and was therefore assumed to support keratin damage by TA via subsequent oxidation of the cleaved disulphide bonds in the nail.

\section{ACKNOWLEDGEMENTS}

Thank you to MedPharm Ltd for financial support. 


\section{FIGURES AND TABLES}

Fig. 1. Measured cell potentials, $E$ vs. SHE (standard hydrogen electrode) plotted against a) the natural $\log$ of TA concentration $(\mathrm{pH} 2.0-2.9)$ at the carbon ( $\mathbf{\square})$ electrode and $b$ ) the natural $\log$ of urea $\mathrm{H}_{2} \mathrm{O}_{2}$ concentration ( $\mathrm{pH}$ range $3.4-4.2$ ) at the platinum ( $\square$ ) electrode.

Fig. 2. Measured cell potentials, $E$ vs. SHE (standard hydrogen electrode) plotted against a) the $\mathrm{pH}$ of TA $(5 \% \mathrm{w} / \mathrm{w})$ at the carbon ( $)$ electrode and b) the $\mathrm{pH}$ of urea $\mathrm{H}_{2} \mathrm{O}_{2}\left(2.5 \% \mathrm{H}_{2} \mathrm{O}_{2}\right.$ w/w) at the platinum ( $\left.\square\right)$ electrode.

Fig. 3. Differential pulse voltammograms of $5 \mathrm{mM}$ thioglycolic acid (TA) at a glassy carbon electrode at a) $\mathrm{pH} \mathrm{2,} \mathrm{b)} \mathrm{pH} 8$ and c) $\mathrm{pH} 13$ (V is versus the standard hydrogen electrode, SHE). Blank traces i.e. DPV of the relevant solvent are subtracted. Inset a): shows a small peak for TA at $\mathrm{pH} 2$ magnified.

Fig. 4. Differential pulse voltammograms of urea hydrogen peroxide (urea $\mathrm{H}_{2} \mathrm{O}_{2}, 5$ $\mathrm{mM} \mathrm{H}_{2} \mathrm{O}_{2}$ ) at a platinum carbon electrode at a) $\mathrm{pH} \mathrm{2,} \mathrm{b)} \mathrm{pH} 8$ and c) $\mathrm{pH} 13(\mathrm{~V}$ is versus the standard hydrogen electrode, SHE). Blank traces i.e. DPV of the relevant solvent are subtracted.

Fig. 5. A typical example of the mean cumulative permeation of terbinafine hydrochloride per unit area following treatment of nails with $15 \%$ thioglycolic acid (TA) for $20 \mathrm{~h}$ at $\mathrm{pH} 2(\bullet)$ or $\mathrm{pH} 8(\circ)$ followed by $15 \%$ urea hydrogen peroxide (urea $\mathrm{H}_{2} \mathrm{O}_{2}$ ) for $20 \mathrm{~h}$ (points represent mean $\pm \mathrm{SD}, n=6$ ). 
Table. 1. The rate of in vitro terbinafine hydrochloride flux $\left(\mu \mathrm{g} / \mathrm{cm}^{2} / \mathrm{h}\right.$, mean $\pm \mathrm{SD}$, $n=6)$ through full thickness nails alone and following pre-treatment according to eight different regimes and the corresponding percentage increase in nail weight (mean \pm $\mathrm{SD}, n=10$ ) observed using identical treatment regimes. 
RESULTS

$\mathbf{a}$

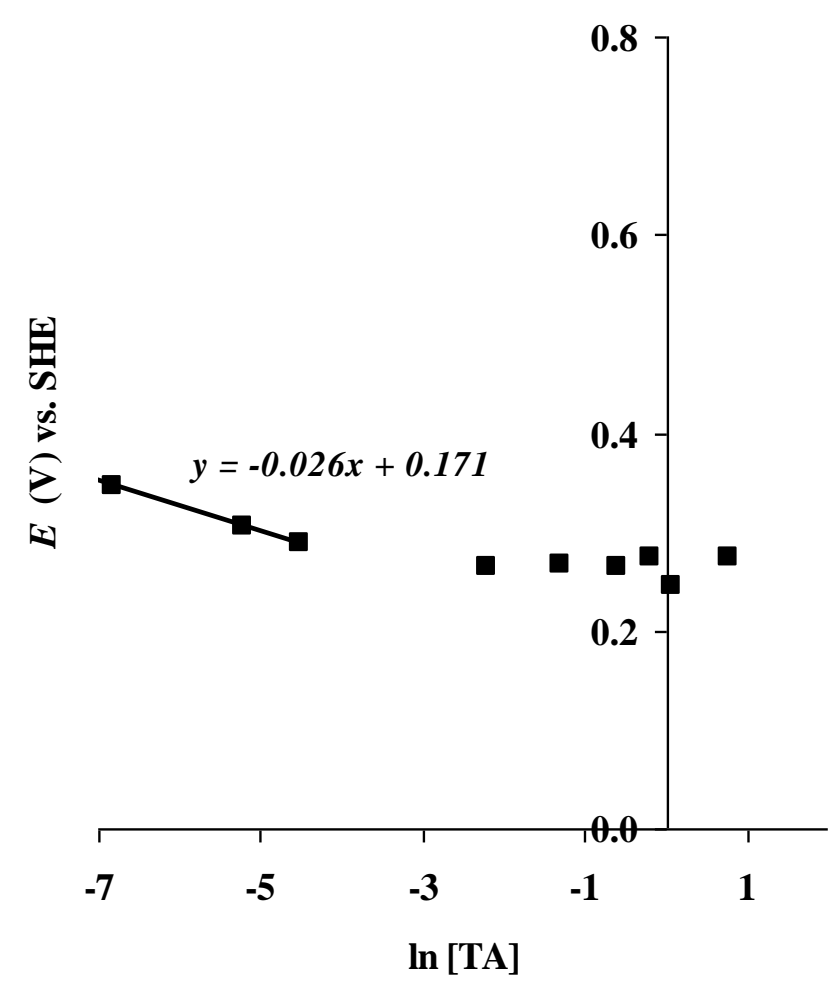

b

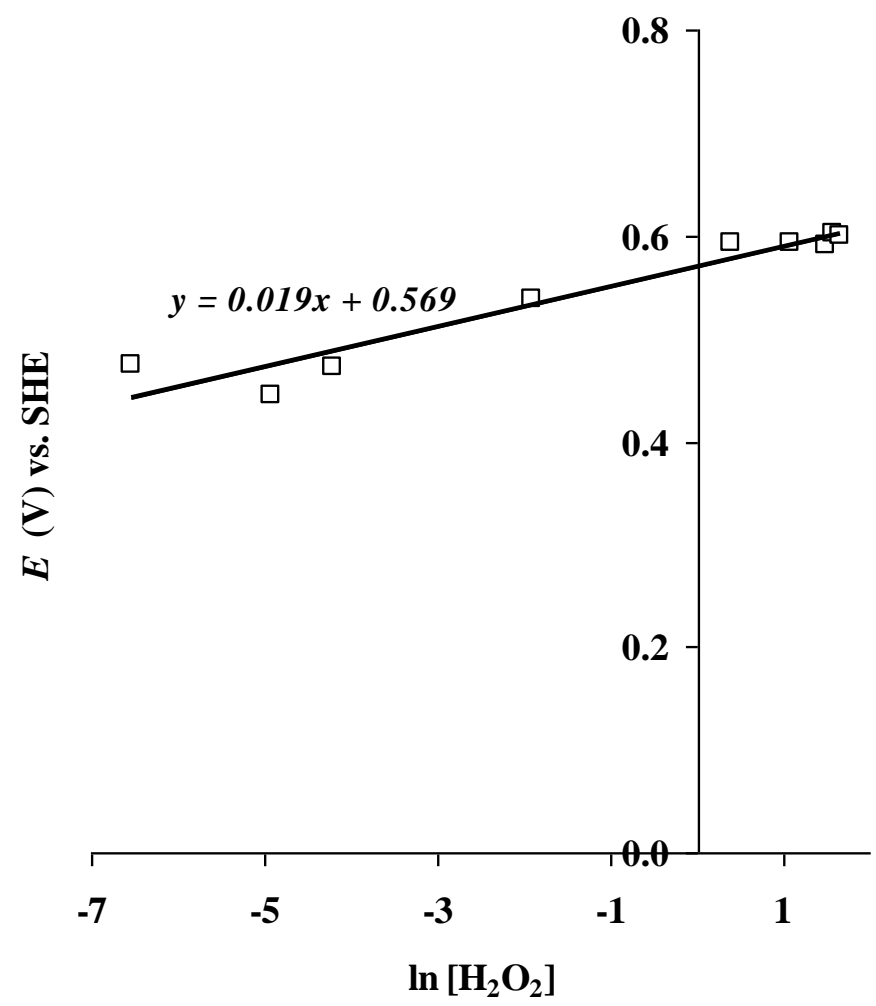

Fig 1 
$\mathbf{a}$

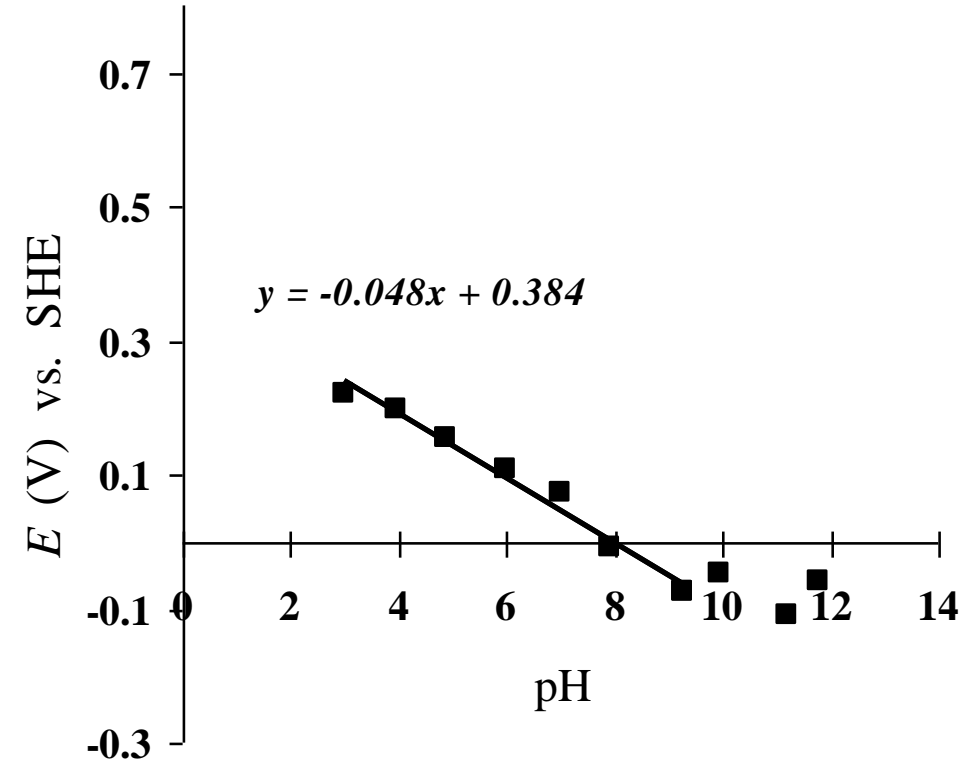

b

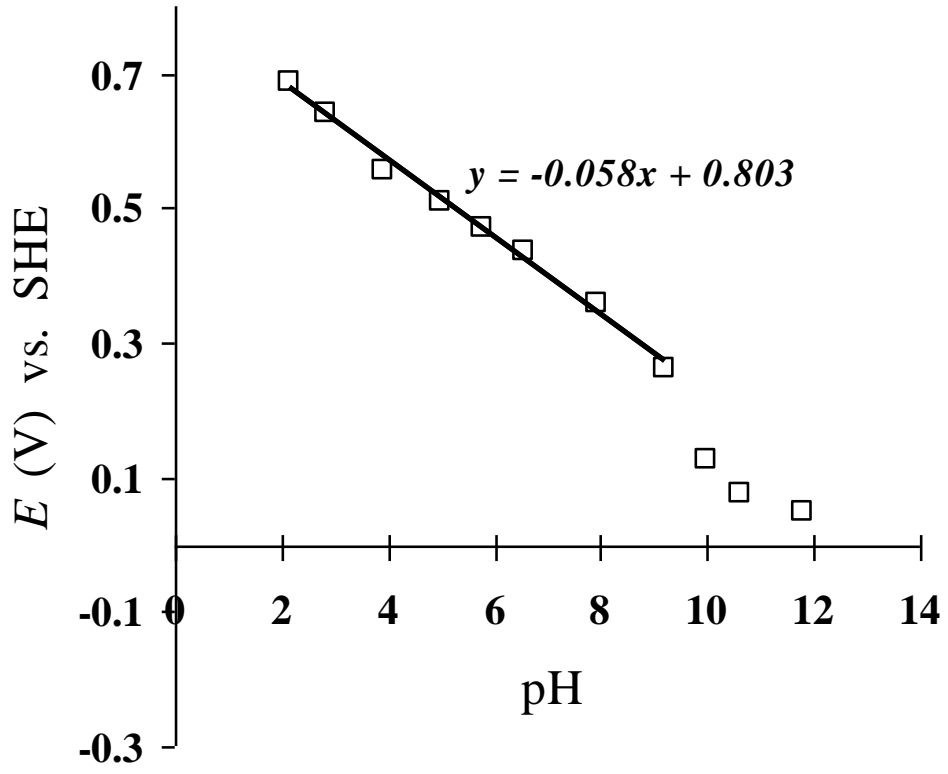

Fig. 2 


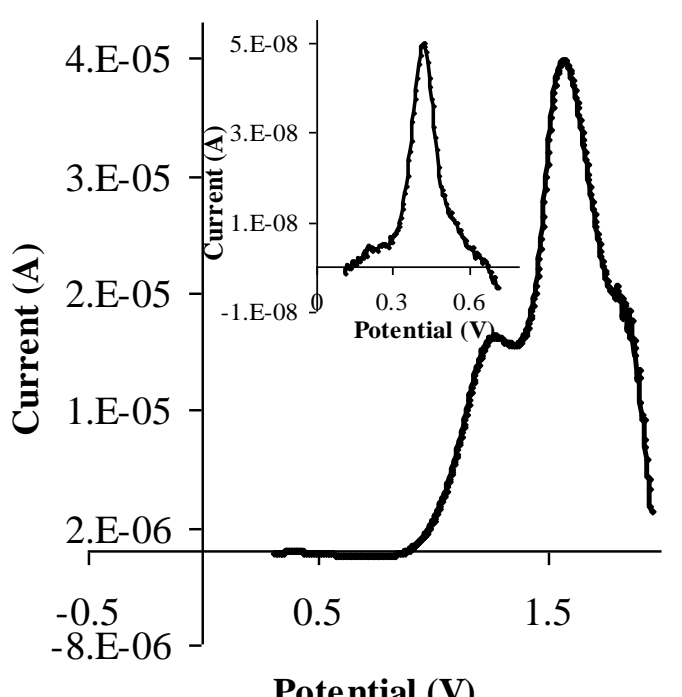

b

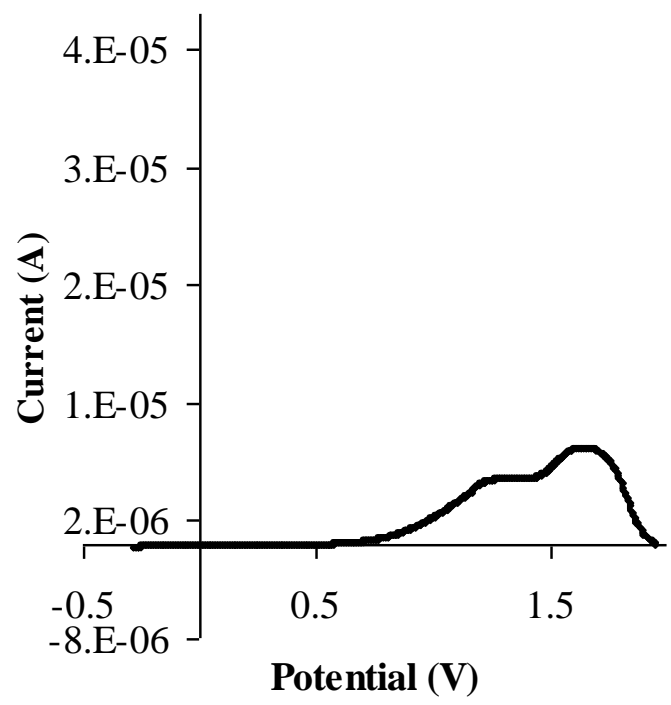

c

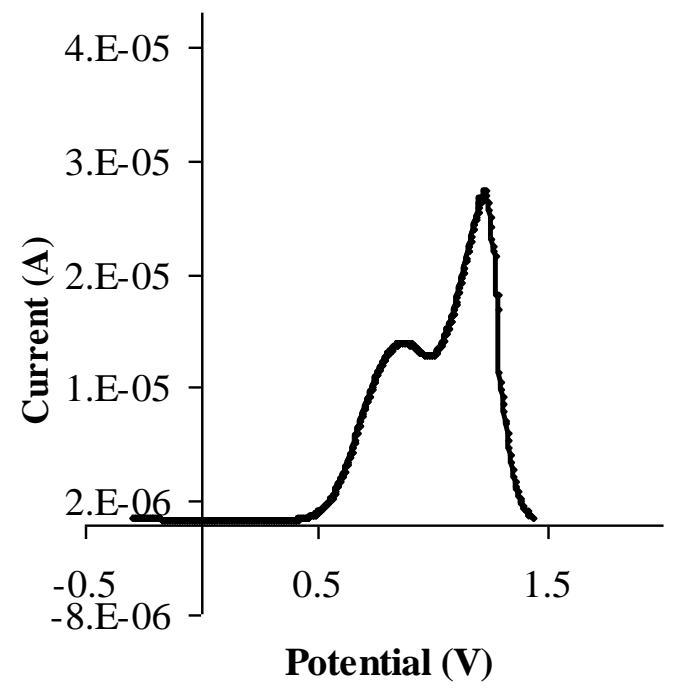

Fig. 3 


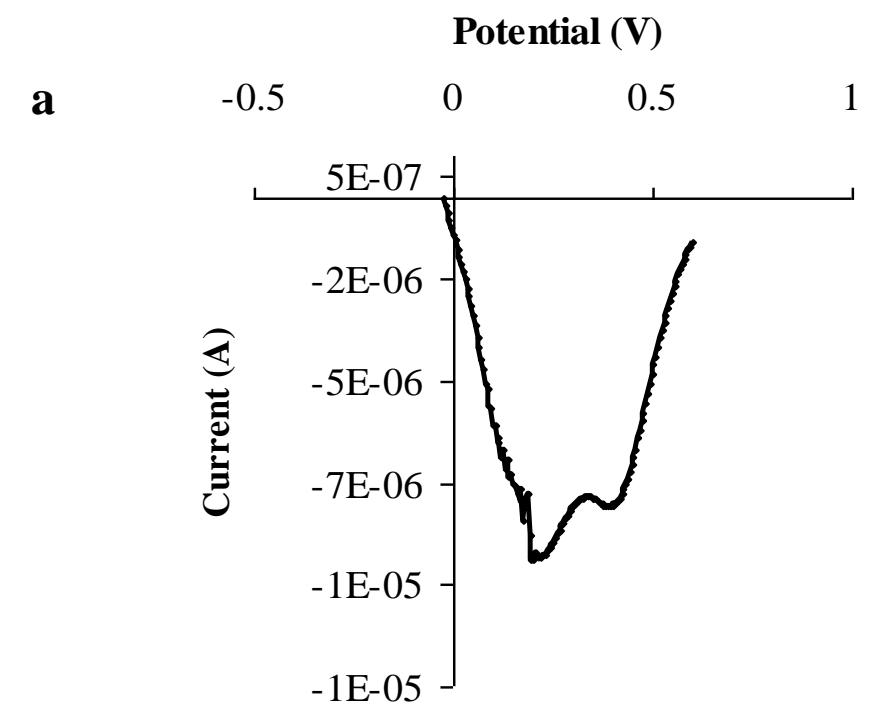

Potential (V)
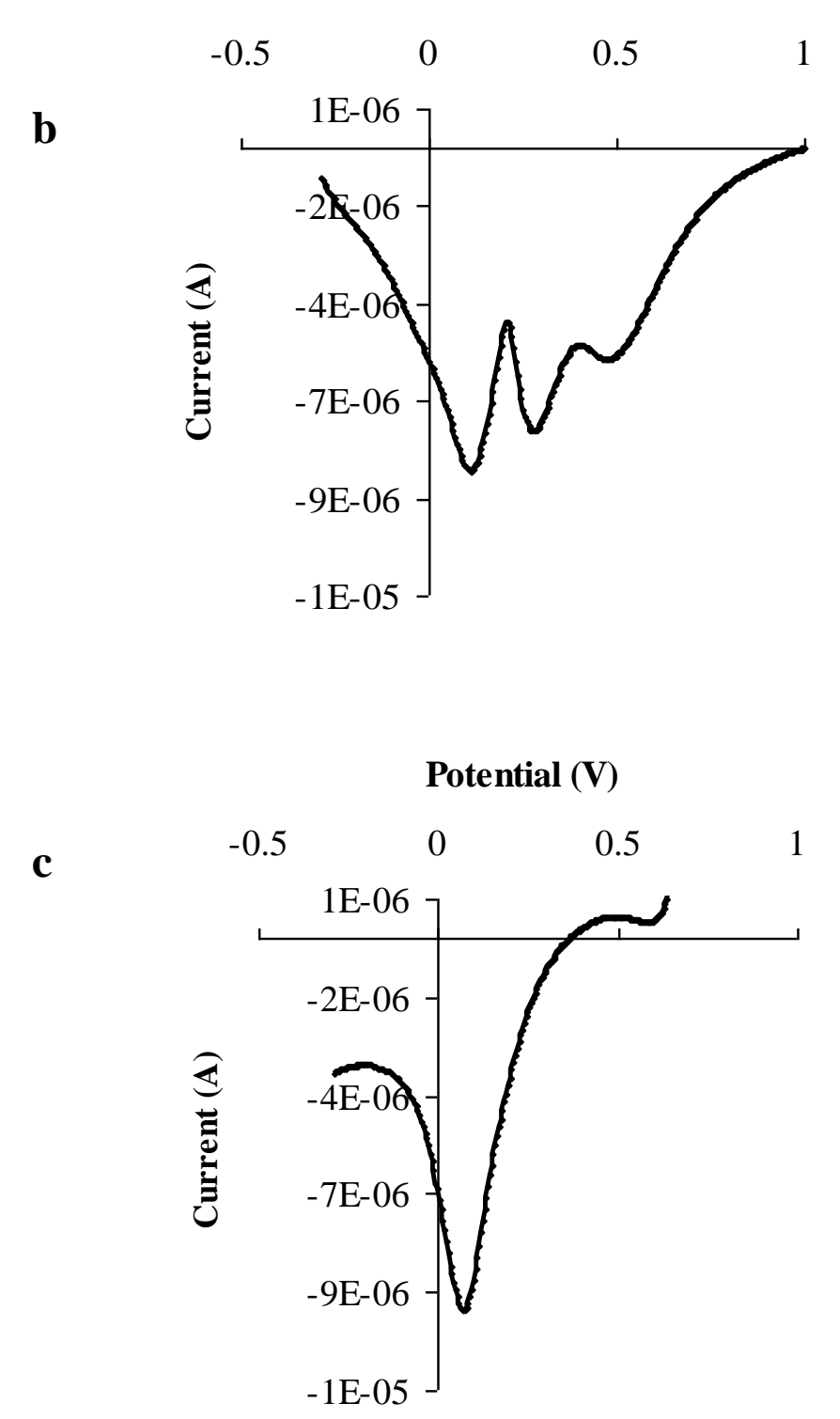

Fig. 4 


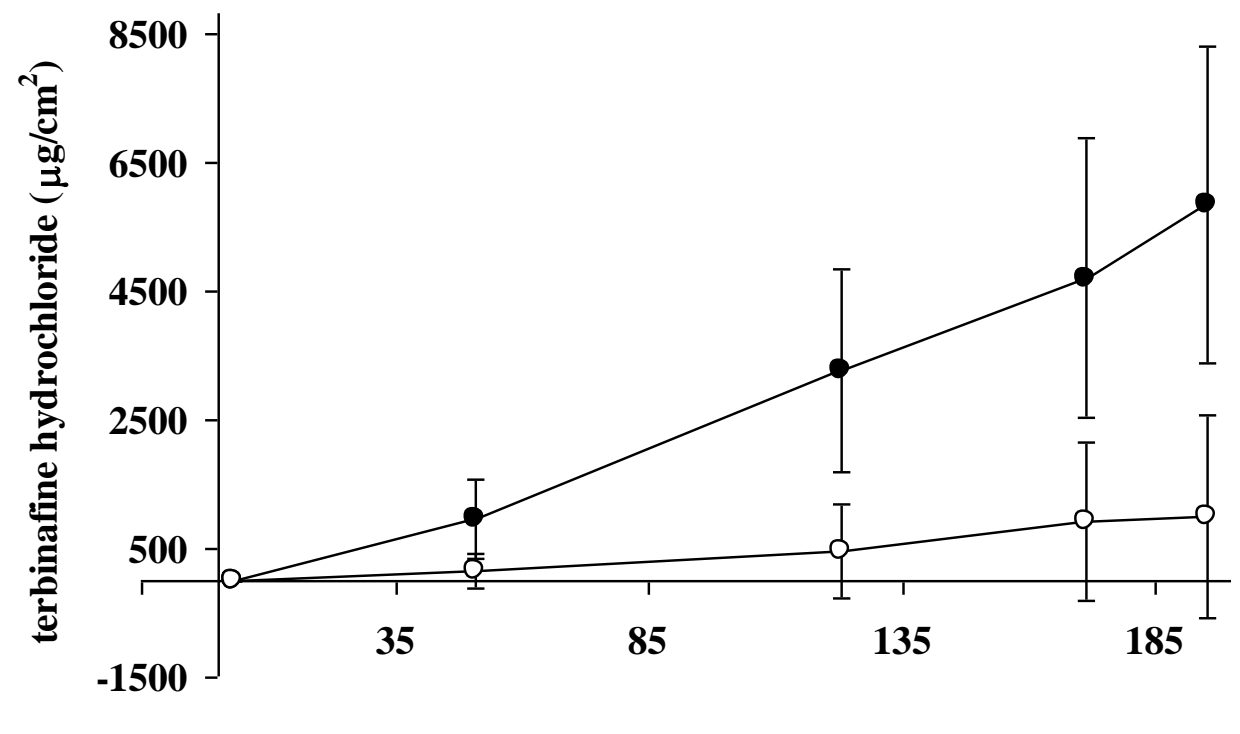

Time (h)

Fig. 5 


\section{Table 1}

\begin{tabular}{|c|c|c|}
\hline Pre-treatment regime & $\underset{\left(\mu \mathrm{g} / \mathrm{cm}^{2} / \mathrm{h}\right)}{\text { Flux }}$ & $\begin{array}{c}\% \text { increase in nail } \\
\text { weight }\end{array}$ \\
\hline $5 \%$ TA pH 2 - $15 \%$ urea $\mathrm{H}_{2} \mathrm{O}_{2}$ pH 3.4 & $14.20 \pm 11.69$ & $139.06 \pm 24.95$ \\
\hline $15 \%$ TA pH $2-15 \%$ urea $\mathrm{H}_{2} \mathrm{O}_{2}$ pH 3.4 & $38.51 \pm 10.94$ & $244.10 \pm 14.99$ \\
\hline $5 \%$ TA pH 8- $15 \%$ urea $\mathrm{H}_{2} \mathrm{O}_{2}$ pH 3.4 & $2.42 \pm 2.07$ & $70.95 \pm 6.31$ \\
\hline $15 \%$ TA pH 8-15 \% urea $\mathrm{H}_{2} \mathrm{O}_{2}$ pH 3.4 & $3.60 \pm 2.73$ & $93.19 \pm 11.73$ \\
\hline $5 \%$ TA pH $5-5 \%$ urea $\mathrm{H}_{2} \mathrm{O}_{2}$ pH 2 & $0.03 \pm 0.07$ & $75.42 \pm 22.33$ \\
\hline $5 \%$ TA pH $5-15 \%$ urea $\mathrm{H}_{2} \mathrm{O}_{2}$ pH 2 & $1.09 \pm 0.86$ & $104.58 \pm 9.21$ \\
\hline $5 \%$ TA pH 5-5\% urea $\mathrm{H}_{2} \mathrm{O}_{2}$ pH 8 & $0.08 \pm 0.22$ & $65.51 \pm 11.30$ \\
\hline $5 \%$ TA pH 5 - $15 \%$ urea $\mathrm{H}_{2} \mathrm{O}_{2}$ pH 8 & $3.26 \pm 2.09$ & $145.09 \pm 38.87$ \\
\hline Control of TBF only & $0.55 \pm 0.71$ & $121.39 \pm 14.13$ \\
\hline
\end{tabular}


Reference List

[1] Gupchup, G. V.; Zatz, J. L. Structural characteristics and permeability properties of the human nail: A review. J. Cosmet. Sci. 50:363-385; 1999.

[2] Walters, K. A.; Flynn, G. L.; Marvel, J. R. Physicochemical characterization of the human nail .1. Pressure sealed apparatus for measuring nail plate permeabilities. $J$. Invest. Dermatol. 76:76-79; 1981.

[3] Bulaj, G. Formation of disulfide bonds in proteins and peptides. Biotechnol. Adv. 23:87-92; 2005.

[4] Marshall, R. C.; Orwin, D. F. G.; Gillespie, J. M. Structure and biochemistry of mammalian hard keratin. Electron Microsc. Rev. 4:47-83; 1991.

[5] Creighton, T. E. Disulfide bonds and protein stability. BioEssays 8:57-63; 1988.

[6] Plaza, S.; Gruzinski, R. Homogeneous and heterogeneous thermal decomposition of diphenyl disulphide. Wear 194:212-218; 1996.

[7] McClements, D. J.; Dickinson, E. Molecular basis of protein functionality. Advances in Food Colloids. Dordrecht: Kluwer Academic Publishers Group; 1996:27-76.

[8] Murdan, S. Drug delivery to the nail following topical application. Int. J. Pharm. 236:1-26; 2002.

[9] Scher, R. K.; Baran, R. Onychomycosis in clinical practice: factors contributing to recurrence. Br. J. Dermatol. 149:5-9; 2003. 
[10] Brown, M. B.; Khengar, R. H.; Turner, R. B.; Forbes, B.; Traynor, M. J.; Evans, C. R. G.; Jones, S. A. Overcoming the nail barrier: A systematic investigation of ungual chemical penetration enhancement. Int. J. Pharm. 370:61-67; 2009.

[11] Khengar, R. H.; Jones, S. A.; Turner, R. B.; Forbes, B.; Brown, M. B. Nail swelling as a pre-formulation screen for the selection and optimisation of ungual penetration enhancers. Pharm. Res. 24:2207-2212; 2007.

[12] Olsen, E. A. Methods of hair removal. J. Am. Acad. Dermatol. 40:143-155; 1999.

[13] Cannell, D. W. Permanent waving and hair straightening. Clin. Dermatol. 6:71-82; 1988.

[14] Robbins, C. R. Chemical and physical behaviour of human hair: New York: Springer-Verlag; 2002.

[15] Marmer, W. N.; Dudley, R. L. The oxidative degradation of keratin (wool and bovine hair). J. Am. Leather Chem. Assoc. 101:408-415; 2006.

[16] Traynor, M. J., Turner, R. B., Evans, C. R. G., Khengar, R. H, Zhang, L., Jones, S. A., and Brown, M. B. A novel permeation enhancer designed to increase the permeation of currently marketed nail lacquers through human nail. Brain, K. R. and Walters, K. A. 11, 90. Cardiff, STS Publishing. 2008.

[17] Compton, R. G.; Saunders, G. H. W. Electrode potentials: Oxford: Oxford University Press; 2002.

[18] Maddock, W. G.; Coller, F. A. The role of the extremities in the dissipation of heat. Am. J. Physiol. 106:589-596; 1933. 
[19] Lawrence, J. N. Electrical resistance and tritiated water permeability as indicators of barrier integrity of in vitro human skin. Toxicol. in Vitro 11:241-249; 1997.

[20] Cammen, L. M. Use of liquid scintillation-counting of Cr-51 and C-14 in twin tracer method of measuring assimilation efficiency. Oecologia 30:249-251; 1977.

[21] Capozzi, G.; Modena, G. Oxidation of thiols. In: Patai, S. eds. The chemistry of the thiol group. John Wiley and Sons Ltd; 1974:785-840.

[22] Rieger, P. H. Electrochemistry: Dordrecht: Springer; 1994.

[23] Bonini, M. G.; Augusto, O. Carbon dioxide stimulates the production of thiyl, sulfinyl, and disulfide radical anion from thiol oxidation by peroxynitrite. J. Biol. Chem. 276:9749-9754; 2001.

[24] Houk, J.; Singh, R.; Whitesides, G. M. Measurement of thiol disulfide interchange reactions and thiol pka values. Methods Enzymol. 143:129-140; 1987.

[25] Krishtalik, L. I. pH-dependent redox potential: how to use it correctly in the activation energy analysis. Biochim. Biophys. Acta-Bioenergetics 1604:13-21; 2003.

[26] Shahrokhian, S.; Yazdani, J. Electrocatalytic oxidation of thioglycolic acid at carbon paste electrode modified with cobalt phthalocyanine: application as a potentiometric sensor. Electrochim. Acta 48:4143-4148; 2003.

[27] Tan, W. T.; Bond, A. M.; Ngooi, S. W.; Lim, E. B.; Goh, J. K. Electrochemical oxidation of L-cysteine mediated by a fullerene-C-60-modified carbon electrode. Anal. Chim. Acta 491:181-191; 2003. 
[28] Shahrokhian, S.; Hamzehloei, A.; Thaghani, A.; Mousavi, S. R. Electrocatalytic oxidation of 2-thiouracil and 2-thiobarbituric acid at a carbon-paste electrode modified with cobalt phthalocyanine. Electroanalysis 16:915-921; 2004. 